\title{
The Joint Effect of Interleukin-12B rs3212227 Genotype and Behavioral Factors on Oral Cancer Risk in Taiwanese
}

\author{
CHING-HAO LI ${ }^{1 *}$, KUO-TING SUN $^{2 *}$, XIN LI $^{1 *}$, LIANG-CHUN SHIH ${ }^{1,3,4}$, LIANG-YU CHEN $^{3}$, CHIEN-CHIH YU ${ }^{4}$, \\ YUN-CHI WANG ${ }^{4}$, WEN-SHIN CHANG ${ }^{1,4}$, CHIA-WEN TSAI ${ }^{1,4}$, CHI-YUAN LI $^{1}$ and DA-TIAN BAU ${ }^{1,4,5}$ \\ ${ }^{1}$ Graduate Institute of Biomedical Sciences, China Medical University, Taichung, Taiwan, R.O.C.; \\ ${ }^{2}$ Division of Pediatric Dentistry, China Medical University Hospital, Taichung, Taiwan, R.O.C.; \\ ${ }^{3}$ Department of Otorhinolaryngology, China Medical University Hospital, Taichung, Taiwan, R.O.C.; \\ ${ }^{4}$ Terry Fox Cancer Research Laboratory, Translational Medicine Research Center, \\ China Medical University Hospital, Taichung, Taiwan, R.O.C.; \\ ${ }^{5}$ Department of Bioinformatics and Medical Engineering, Asia University, Taichung, Taiwan, R.O.C.
}

\begin{abstract}
Background/Aim: Oral cancer is of the highest incidence worldwide in Taiwan, and a better marker for personalized therapeutic strategies such as immunotherapies is urgently needed. Interleukin-12 (IL12) is a cytokine that has been reported to exhibit potent tumoricidal effects, however, its genotypic contribution to oral cancer is still largely unknown. The current study aimed at investigating whether IL12B rs3212227 genotype is associated with oral cancer in Taiwan. Materials and Methods: Genotypic characteristics of IL12B rs3212227 were determined among 958 oral cancer cases and age- and gender-matched individuals via typical polymerase chain reaction-restriction fragment length polymorphism (PCR-RFLP) methodology. Results: The AA, AC and CC genotypes of IL12B rs3212227 were $38.2,38.9$ and $22.9 \%$ in the case group and 36.2, 41.5 and $22.3 \%$ in the control group $(p=0.5189)$, respectively. Conclusion: IL12B rs3212227 genotype was associated with oral cancer risk only in betel quid chewers.
\end{abstract}

According to the 2017 Statistics of Causes of Death published by the Ministry of Health and Welfare, oral cancer is the fourth most common male cancer and the fourth leading cause of male cancer death in Taiwan, where the

*These Authors contributed equally to this study.

Correspondence to: Da-Tian Bau, Terry Fox Cancer Research Laboratory, Translational Medicine Research Center, China Medical University Hospital, 2 Yuh-Der Road, Taichung, 404 Taiwan, R.O.C. Tel: +886 422053366 (Ext. 5805), e-mail: datian@ mail.cmuh.org.tw; artbau2@gmail.com

Key Words: Alcohol drinking, betel quid, genotype, interleukin-12B, oral cancer, polymorphism, smoking, Taiwan. incidence of oral cancer is the highest in the world $(1,2)$. Epidemiological studies have shown that the development and susceptibility to oral cancer of Taiwan citizens is determined by genomic variations (such as single nucleotide polymorphisms) and behavioral factors (such as alcohol/tobacco/areca-nut consumptions, bad brushing and dental implanting habits, and viral infectious status) (3-6). Thus, a better target or marker for advanced personalized therapeutic approaches such as immunotherapies is an urgent need. In pursuit of this aim, studies have provided increasing evidence that specific genotypes are associated with increased oral cancer risk in cigarette smokers $(4,5)$, betel quid chewers $(6,7)$ compared with non-smokers and nonchewers $(8,9)$. These reports are extremely valuable for elucidating the contribution of genomic, environmental and behavioral factors in oral cancer etiology and providing a better consulting system for therapeutic decision and genomic pharmacology of oral cancer in the era of personalized and precise medicine.

Interleukin 12 (IL12) is a multi-functional cytokine originally identified as stimulatory factor for natural killer cells and maturation factor for lymphocytes $(10,11)$. In addition, IL12 has been found to stimulate the cytolytic capacity of natural killer cells, and activate their capacity in cytokine production, particularly of interferon- $\gamma(12,13)$. Furthermore, IL12 has been reported to serve in bridging innate and adaptive immunity by promoting the differentiation of T-helper 1 cells $(14,15)$. In animal model experiments, IL12 has been found to have antitumor effects since mice lacking IL12 subunit p35 had earlier development and more papillomas compared with those wild-type ones (16). Mice deficient in IL12 receptor chain IL12R $\beta 2$ also had faster growth of B16 melanomas than wild-type ones (17). Finally, exogenous administration of IL12 significantly suppressed the growth of sarcoma, melanoma, lung carcinoma and breast 
carcinoma transplants in mouse models (18-20). Most interesting, although IL12 has certain side-effects, its curative effect is impressive and significant in clinical settings. For instance, IL12 phase I/II trials in patients with B-cell lymphoma or Kaposi sarcoma were both very successful in 2002 and $2007(21,22)$. IL12 treatment can have synergistic effects with IL18 on restoring intratumoral natural killer cell functions in major histocompatibility complex class I-deficient tumors $(21,22)$. Combined with natural killer cell-secreted interferon- $\gamma$, IL12 can inhibit tumor angiogenesis and suppress tumor growth (23).

The human $I L 12 B$ gene is located at human chromosome 5. $I L 12 B$ rs3212227 is a polymorphic site located in the 3'untranslated region, and may influence the level of production of IL12 via disruption of exonic splicing for IL12 $(24,25)$. In literature, the contribution of $I L 12 B$ to oral cancer has not been investigated to our knowledge, let alone the joint effects of $I L 12 B$ genotype with behaviors such as betel quid chewing on oral cancer risk. Therefore, in the current study, the contribution of $I L 12 B$ genotype to the risk of oral cancer, as well as the interaction of $I L 12 B$ genotype and behavioral factors, including smoking, alcohol drinking and betel quid chewing, were investigated among Taiwanese.

\section{Materials and Methods}

Population sampling methodology. Nine hundred and fifty-eight patients diagnosed with oral cancer were recruited with help from the cancer team at the Outpatient Clinics of General Surgery from China Medical University Hospital; the clinical characteristics of patients, including histological details, were all graded and defined by experts in pathology. Patients with history of any other cancer were excluded from the databank, and all participants were Taiwanese and voluntarily completed a self-administered questionnaire and provided their blood sample for genotyping studies. The same number of healthy volunteers was selected as controls by matching for age, gender, and behavioral factors such as alcohol, tobacco, and areca nut consumption after initial random sampling from the Health Examination Cohort of China Medical University Hospital. The exclusion criteria for the controls included previous malignancy, metastasized cancer from other or unknown origin and any genetic or familial disease. The study was approved by the Institutional Review Board of the China Medical University Hospital (DMR101-IRB1-306) and written informed consent was obtained from all participants. Selected characteristics of the investigated groups are summarized in Table I.

IL12B PCR-RFLP methodology. The genomic DNA from the peripheral blood leucocytes of each case and control was prepared with QIAamp Blood Mini Kit (Blossom, Taipei, Taiwan) $(26,27)$, aliquoted, stored and further processed in typical PCR-RFLP genotyping processes as our previous articles $(26,27)$. The primer sequences for $I L 12 B$ genotyping were all designed following those designed by Chen and colleagues (24), as validated by our previous articles $(28,29)$. The PCR cycling was set as: one cycle at $94^{\circ} \mathrm{C}$ for $5 \mathrm{~min} ; 35$ cycles of $94^{\circ} \mathrm{C}$ for $30 \mathrm{~s}, 55^{\circ} \mathrm{C}$ for $30 \mathrm{~s}$, and $72^{\circ} \mathrm{C}$ for $30 \mathrm{~s}$; and a final extension at $72^{\circ} \mathrm{C}$ for $10 \mathrm{~min}$. The primers of $I L 12 B$
Table I. Selected characteristics of the 958 patients with oral cancer and 958 controls.

\begin{tabular}{lccc}
\hline Characteristic & $\begin{array}{c}\text { Controls } \\
(\mathrm{n}=958)\end{array}$ & $\begin{array}{c}\text { Cases } \\
(\mathrm{n}=958)\end{array}$ & $p$-Value \\
\hline Age, years & & & \\
$\quad$ Mean \pm SD & $56.8 \pm 8.7$ & $56.4 \pm 7.5$ & $0.3755^{\mathrm{a}}$ \\
Gender, $\mathrm{n}(\%)$ & $728(76.0 \%)$ & $728(76.0 \%)$ & $>0.99 \mathrm{~b}$ \\
Male & $230(24.0 \%)$ & $230(24.0 \%)$ & \\
Female & & & \\
Personal habit, $\mathrm{n}(\%)$ & $668(69.7 \%)$ & $718(74.9 \%)$ & $\mathbf{0 . 0 1 0 7}^{\mathrm{b}}$ \\
Cigarette smoking & $642(67.0 \%)$ & $684(71.4 \%)$ & $\mathbf{0 . 0 3 7 7}^{\mathrm{b}}$ \\
Alcohol drinking & $508(53.0 \%)$ & $773(80.7 \%)$ & $<\mathbf{0 . 0 0 0 1}$ \\
Betel quid chewing & & \\
Primary tumor site, $\mathrm{n}(\%)$ & & $397(41.4 \%)$ & \\
Tongue & & $356(37.2 \%)$ & \\
Buccal mucosa & & $39(4.1 \%)$ & \\
Mouth floor & & $33(3.4 \%)$ & \\
Retromolar trigone & & $29(3.0 \%)$ & \\
Alveolar ridge & & $27(2.8 \%)$ & \\
Palate & & $39(4.1 \%)$ & \\
Lip & & $38(4.0 \%)$ & \\
Other & &
\end{tabular}

SD: Standard deviation. aBased on Student's $t$-test; bBased on chisquare test. Significant $p$-values $(p<0.05)$ are shown in bold.

rs3212227 were 5'-GATATCTTTGCTGTATTTGTATAGTT-3' (forward) and 5'-AATATTTAAATAGCATGAAGGC-3' (reverse), which generated a 118-bp fragment. The fragment was then digested by Taq I (New England BioLabs, Ipswich, MA, USA). The variant allele $I L 12 B$ rs $3212227 \mathrm{C}$ produced two fragments of 92 and $26 \mathrm{bp}$, and the wild-type allele $I L 12 B$ rs3212227A resulted in a single 118 bp fragment. Each step in genotyping and analysis was performed by at least two of the researchers independently and blindly.

Statistical methodology. All individuals with both genotypic and complete records for characteristics listed in Table I were included in the final analysis. Student's $t$-test and Pearson's chi-square test were used for comparing the difference in age between case and control groups, and the distribution of $I L 12 B$ genotypes between the case and control groups, respectively. The associations between the $I L 12 B$ genotype and cancer susceptibility were estimated by computing odds ratios (ORs) and their $95 \%$ confidence intervals (CIs) from logistic regression analysis. Any comparison with a value of $p<0.05$ was considered as statistically significant.

\section{Results}

The basic characteristics, including age, gender and personal habits tumor site and clinical data, for the 958 patients with oral cancer and the same number of matched controls are summarized in Table I. There was no difference between the case and control groups in age and gender $(p=0.3755$ and $>0.99$, respectively; Table I). There were significantly higher percentages of smokers, alcohol drinkers and betel quid 
Table II. Distribution of interleukin-12B (IL12B) rs3212227 genotypes among the patients with oral cancer and healthy controls.

\begin{tabular}{|c|c|c|c|c|}
\hline IL12B rs3212227 Genotype & $\begin{array}{c}\text { Cases } \\
n\end{array}$ & $\begin{array}{c}\text { Controls } \\
\mathrm{n}\end{array}$ & OR $(95 \% \mathrm{CI})$ & $p$-Value ${ }^{a}$ \\
\hline AA & $366(38.2 \%)$ & $347(36.2 \%)$ & 1.00 (Reference) & \\
\hline $\mathrm{AC}$ & $373(38.9 \%)$ & $397(41.5 \%)$ & $0.89(0.73-1.09)$ & 0.2659 \\
\hline $\mathrm{CC}$ & $219(22.9 \%)$ & $214(22.3 \%)$ & $0.97(0.76-1.23)$ & 0.8042 \\
\hline $\mathrm{AC}+\mathrm{CC}$ & $591(61.8 \%)$ & $611(63.8 \%)$ & $0.92(0.76-1.10)$ & 0.3598 \\
\hline$P_{\text {trend }}$ & & & & 0.5189 \\
\hline
\end{tabular}

OR: Odds ratio; CI: confidence interval. aBased on chi-square without Yate's correction test.

Table III. Distribution of interleukin-12B (IL12B) rs3212227 allelic frequencies among the patients with oral cancer and healthy controls.

\begin{tabular}{lcccc}
\hline$I L 12 B$ rs3212227 & Cases, $\mathrm{n}(\%)$ & Controls, $\mathrm{n}(\%)$ & OR (95\% CI) & $p$-Value ${ }^{\mathrm{a}}$ \\
\hline Allele A & $1105(57.7 \%)$ & $1091(56.9 \%)$ & 1.00 (reference) & 0.6475 \\
Allele C & $811(42.3 \%)$ & $825(43.1 \%)$ & $0.97(0.85-1.10)$ & 0 \\
\hline
\end{tabular}

OR: Odds ratio; CI: confidence interval. ${ }^{a}$ Based on chi-square without Yate's correction test.

chewers in the oral cancer group than those in the age- and gender-matched control group ( $p=0.0107,0.0377$ and 0.0001 , respectively) (Table I). The most prevalent oral cancer tumor sites were tongue $(41.4 \%)$ and buccal mucosa (37.2\%) among the investigated Taiwan oral cancer population (Table I).

The distribution of genotypic frequencies of ILI2B rs3212227 for all the investigated Taiwanese is summarized and compared in Table II. There was no significant difference in the distribution of $I L 12 B$ rs3212227 genotypes between the oral cancer and control groups ( $p$ for trend $=0.5189$ ). In detail, the frequencies of the heterozygous variant $\mathrm{AC}$ of $I L 12 B$ rs 3212227 were $38.9 \%$ in the oral cancer group, a little lower than $41.5 \%$ in the control group. On the contrary, the frequencies of the homozygous variant $\mathrm{CC}$ of $I L 12 \mathrm{~B}$ rs3212227 were $22.9 \%$ in the oral cancer group, a little higher than the $22.3 \%$ in the control group. Neither the $\mathrm{AC}(\mathrm{OR}=0.89$, $95 \% \mathrm{CI}=0.73-1.09, p=0.2659)$ nor $\mathrm{CC}(\mathrm{OR}=0.97,95 \%$ $\mathrm{CI}=0.76-1.23, p=0.8042)$ genotypes at $I L 12 B$ rs3212227 seemed to be a potential biomarker for oral cancer in Taiwanese. The analysis of $\mathrm{AC}+\mathrm{CC}$ combined versus AA also revealed that the genotypes of $I L 12 B$ rs3212227 were not differentially distributed in the control and case groups $(\mathrm{OR}=0.92,95 \% \mathrm{CI}=0.76-1.10, p=0.3598)$ (Table II).

The distribution of allelic frequencies of rs3212227 in $I L 12 B$ is shown in Table III. Consistent with the findings in Table II, the allelic frequencies of variant $C$ or wild-type $A$ at $I L 12 B$ rs3212227 were not differentially distributed between case and control groups $(\mathrm{OR}=0.97,95 \% \mathrm{CI}=0.85$ $1.10, p=0.6475)$. In detail, the frequencies of the $\mathrm{A}$ and $\mathrm{C}$ alleles of $I L 12 B$ rs 3212227 were 57.7 and $42.3 \%$ among the patients with oral cancer and 56.9 and $43.1 \%$ among controls (Table III).

Since personal behaviors, including cigarette smoking, alcohol drinking and betel quid chewing, may contribute to oral cancer risk (Table I), we are also interested in the interaction of the genotype of $I L 12 B$ rs3212227 with these in the investigated Taiwanese population. The joint effects of $I L 12 B$ rs3212227 with smoking, alcohol drinking and betel quid chewing status on oral cancer risk determining were examined and results are presented in Tables IV, $\mathrm{V}$ and VI. In the analysis, both the patient and matched control groups were stratified according to their smoking status and the ORs and 95\% CI were calculated. The results showed that there was no significant difference in the genotypic distribution among the non-smokers $(p=0.5425)$, smokers ( $p=0.3614)$ (Table IV), non-drinkers $(p=0.8395)$, or drinkers ( $p=0.4126$ ) (Table V). Interestingly, the percentages of AA and CC genotypes at ILI2B rs3212227 were both higher in the case group than those in the control group for the betel quid chewers $(p=0.0390)$ (Table VI). On the contrary, there was no difference in the genotypic distribution among the non-chewers $(p=0.2092)$.

\section{Discussion}

In the current study, the contribution of genotype to oral cancer risk was firstly investigated all over the world. The examined samples are presented in Table I. From the genotyping results of 958 patients with oral cancer and 958 age- and gender-matched healthy controls, it was found that 
Table IV. Distribution of interleukin-12B (IL12B) rs3212227 genotypes among oral cancer cases and controls after stratification by smoking status.

\begin{tabular}{|c|c|c|c|c|c|}
\hline \multirow[t]{2}{*}{ Behavior status } & & \multicolumn{3}{|c|}{ IL12B rs3212227 genotype, n (\%) } & \multirow[b]{2}{*}{$p$-Value ${ }^{\mathrm{a}}$} \\
\hline & & AA & $\mathrm{AC}$ & $\mathrm{CC}$ & \\
\hline \multirow[t]{2}{*}{ Non-smokers } & Controls & $104(35.9 \%)$ & $123(42.4 \%)$ & $63(21.7 \%)$ & \multirow[t]{2}{*}{0.5425} \\
\hline & Cases & $92(38.3 \%)$ & $105(43.8 \%)$ & $43(17.9 \%)$ & \\
\hline \multirow[t]{2}{*}{ Smokers } & Controls & $243(36.4 \%)$ & $274(41.0 \%)$ & $151(22.6 \%)$ & \multirow[t]{2}{*}{0.3614} \\
\hline & Cases & $274(38.2 \%)$ & $268(37.3 \%)$ & $176(24.5 \%)$ & \\
\hline
\end{tabular}

aBased on chi-square without Yate's correction test.

Table V. Distribution of interleukin-12B (IL12B) rs3212227 genotypes among oral cancer cases and controls after stratification by alcohol drinking status.

\begin{tabular}{|c|c|c|c|c|c|}
\hline \multirow[t]{2}{*}{ Behavior statu } & & \multicolumn{3}{|c|}{ IL12B rs3212227 genotype, n (\%) } & \multirow[b]{2}{*}{$p$-Value ${ }^{\mathrm{a}}$} \\
\hline & & AA & $\mathrm{AC}$ & $\mathrm{CC}$ & \\
\hline \multirow[t]{2}{*}{ Non-drinkers } & Controls & $110(34.8 \%)$ & $132(41.8 \%)$ & $74(23.4 \%)$ & \multirow[t]{2}{*}{0.8395} \\
\hline & Cases & $100(36.5 \%)$ & $115(42.0 \%)$ & $59(21.5 \%)$ & \\
\hline \multirow[t]{2}{*}{ Drinkers } & Controls & $237(36.9 \%)$ & $265(41.3 \%)$ & $140(21.8 \%)$ & \multirow[t]{2}{*}{0.4126} \\
\hline & Cases & $266(38.9 \%)$ & $258(37.7 \%)$ & $160(23.4 \%)$ & \\
\hline
\end{tabular}

aBased on Chi-square without Yate's correction test.

Table VI. Distribution of interleukin-12B (IL12B) rs3212227 genotypes among oral cancer cases and controls after stratification by betel quid chewing status.

\begin{tabular}{|c|c|c|c|c|c|}
\hline \multirow[t]{2}{*}{ Behavior status } & & \multicolumn{3}{|c|}{ IL12B rs3212227 genotype, n (\%) } & \multirow[b]{2}{*}{$p$-Value ${ }^{\mathrm{a}}$} \\
\hline & & AA & $\mathrm{AC}$ & $\mathrm{CC}$ & \\
\hline \multirow[t]{2}{*}{ Non-chewers } & Controls & $168(37.3 \%)$ & $171(38.0 \%)$ & $111(24.7 \%)$ & 0.2092 \\
\hline & Cases & $63(34.1 \%)$ & $84(45.4 \%)$ & $38(20.5 \%)$ & \\
\hline \multirow[t]{2}{*}{ Chewers } & Controls & $179(35.2 \%)$ & $226(44.5 \%)$ & $103(20.3 \%)$ & 0.0390 \\
\hline & Cases & $303(39.2 \%)$ & $289(37.4 \%)$ & $181(23.4 \%)$ & \\
\hline
\end{tabular}

aBased on chi-square without Yate's correction test. Significant $p$-values $(p<0.05)$ are shown in bold.

IL12B rs3212227 (Table II) was not a genomic biomarker for detection and prediction of oral cancer risk among Taiwanese. It was further validated that the C allele of $I L 12 B$ rs3212227 was not associated with altered cancer risk (Table III). These findings support the idea that involvement of IL12 in the carcinogenesis may not simply be critical in regard to the inherited variant of $I L 12 B$ rs3212227 but rather at the post-transcriptional and post-translational levels. Genotype-behavior interaction was not found among the cigarette smokers or alcohol consumers (Tables IV and V).

From the cancer genomic viewpoint, the variant $\mathrm{AC} / \mathrm{CC}$ genotypes at $I L 12 B$ rs3212227 have been associated with increased risk of several types of cancer, including esophageal (30), gastric (31), breast (32), bladder (33), cervical $(24,34)$ and osteosarcoma (35), but some controversial findings have also been reported $(25,36-38)$. A meta-analysis showed that IL12B rs3212227 can potentially serve as a biomarker for cancer risk among Asians, especially for cervical and nasopharyngeal cancer (39). A more updated meta-analysis in 2017 reported that the CC genotype at IL12B rs3212227 was significantly associated with higher overall cancer risk, especially among Asian ethnicities (40). Our results showed that ILI2B rs3212227 genotype was not associated with oral cancer risk (Tables II and III) nor with lung cancer risk (28) among Taiwanese. The frequencies of $\mathrm{AA}$ and $\mathrm{CC}$ genotype of 
$I L 12 B$ rs3212227 were found to be significantly higher in the case group than the control group among betel quid chewers (Table VI). The inconsistent conclusions may arise from different ethnic populations or cancer types investigated. In addition, the genetic background, lifestyle, environmental exposure and immune status were very divergent among the investigated subjects.

The genotype-phenotype correlation of $I L 12 B$ rs 3212227 has been investigated but a conclusive model for its involvement in human diseases, such as cancer has not yet been established. The serum level of IL12 was found to be much higher in patients with type 1 diabetes with $I L 12 B$ rs3212227 AA genotype than those with AC or CC genotypes $(41,42)$. On the contrary, the levels of IL12 were reported to be higher in the peripheral blood mononuclear cells form individuals with CC genotype at IL12B rs3212227 than those with $\mathrm{AC}$ or AA genotypes, upon stimulation with lipopolysaccharide (42).

Another possible interpretation of the inconsistent genotypephenotype correlation is that the serum level of IL12 is under a complicated controlling network. For instance, IL12A and $I L 12 B$ may control the secretion of each other. It has been shown that the presence of the variant genotype IL12B rs3212227 correlated with increased IL12A secretion, but not $I L 12 B$ itself (42). Thus, in the near future, we will investigate whether the $I L 12 A$ genotype may be a practical biomarker for early detection and prediction of oral cancer among Taiwanese. For instance, the AA genotype of $I L 12 A$ rs568408 was found to be significantly associated with higher overall cancer risk, especially among Asian ethnicities (40). In addition, the combinative effects of IL12A and IL12B will be examined.

Smoking, alcohol drinking and betel quid chewing habits are the three major risk factors for oral cancer in Taiwan. In this study, the interaction analysis of the genotype of $I L 12 B$ rs3212227 and these personal behaviors of the participants were further evaluated. The results showed that the percentages of AA and CC genotypes at $I L 12 B$ rs 3212227 were both higher in the case group than those in the control group for the betel quid chewers (Table VI). It is a very unique finding that no genotype at $I L 12 B$ rs3212227 was associated with increased or decreased risk of oral cancer, that is to say, we failed to demonstrate what the difference is and what it means in regard to oral cancer risk (Table VI). On the contrary, there was clearly no differential distribution of genotype among nonchewers (Table VI). The interaction of the genotype of IL12A rs568408 with smoking or alcohol drinking status was not found to be significant (Tables IV and V). In the current study, the phenotypic data are not yet sufficient enough to establish genotype-phenotype correlations among Taiwanese. Further studies using cells primarily cultured from patients in addition to commercially available oral cancer cell lines, are strongly recommended to explore the effects of betel quid compounds on cells with different $I L 12 A$ and IL12B genotypes.
In conclusion, the study indicated that genotype of $I L 12 B$ rs3212227 appears to be a determinant of oral cancer risk among Taiwanese but only in those with betel quid chewing habits.

\section{Conflicts of Interest}

The Authors declare no conflicts of interest with any company or person.

\section{Authors' Contributions}

Research design: $\mathrm{Li} \mathrm{CH}$, Sun $\mathrm{KT}$ and $\mathrm{Li} \mathrm{X}$; patient and questionnaire summary: Shih LC and Chen LY; study performance: Wang YC and Chang WS; statistical analysis: Li CH, Li CY and Tsai $\mathrm{CW}$; article writing: Tsai $\mathrm{CW}$ and Bau DT; reviewing and revising: Chang WS, Tsai CW and Bau DT.

\section{Acknowledgements}

The Authors are grateful to Tissue-bank of China Medical University Hospital and doctors/nurses for their excellent sample collection and technical assistance. Technical assistance from YuChen Hsiau and Hsin-Ting Li and the consultation on statistical analysis from Cheng-Li Lin were very helpful in article preparation. This study was supported mainly by China Medical University Hospital (DMR-108-212) to Dr. Li.

\section{References}

1 Siegel RL, Miller KD and Jemal A: Cancer statistics, 2019. CA Cancer J Clin 69: 7-34, 2019. PMID: 30620402. DOI: 10.3322/caac. 21551

2 Cancer Registry Annual Report 2016, Health Promotion Administration, Ministry of Health and Welfare, Taiwan.

3 Hsu CF, Tseng HC, Chiu CF, Liang SY, Tsai CW, Tsai MH and Bau DT: Association between DNA double-strand break gene $K u 80$ polymorphisms and oral cancer susceptibility. Oral Oncol 45: 789-793, 2009. PMID: 19217823. DOI: 10.1016/ j.oraloncology.2008.12.002

4 Tsai MH, Tseng HC, Liu CS, Chang CL, Tsai CW, Tsou YA, Wang RF, Lin CC, Wang HC, Chiu CF and Bau DT: Interaction of EXO1 genotypes and smoking habit in oral cancer in Taiwan. Oral Oncol 45: e90-94, 2009. PMID: 19515603. DOI: 10.1016/j.oraloncology.2009.03.011

5 Tsai CW, Hsu CF, Tsai MH, Tsou YA, Hua CH, Chang WS, Lin CC and Bau DT: Methylenetetrahydrofolate reductase (MTHFR) genotype, smoking habit, metastasis and oral cancer in Taiwan. Anticancer Res 31: 2395-2399, 2011. PMID: 21737671.

6 Tsou YA, Hua CH, Tseng HC, Hsu CF, Tsai CW, Sun SS, Tsai RY, Tsai MH and Bau DT: The joint effect of hOGGl single nucleotide polymorphism and betel quid chewing on oral cancer in Taiwan. Anticancer Res 30: 4205-4208, 2010. PMID: 21036742.

7 Chung $\mathrm{CM}$, Lee $\mathrm{CH}$, Chen MK, Lee KW, Lan CE, Kwan AL, Tsai MH and Ko YC: Combined genetic biomarkers and betel quid chewing for Identifying high-risk group for oral cancer occurrence. Cancer Prev Res 10: 355-362, 2017. PMID: 28400480. DOI: 10.1158/1940-6207.CAPR-16-0259 
8 Huang YJ, Niu J, Liu Z, Wang LE, Sturgis EM and Wei Q: The functional IGFBP7 promoter $-418 \mathrm{G}>$ A polymorphism and risk of head and neck cancer. Mutat Res 702: 32-39, 2010. PMID: 20599521. DOI: 10.1016/j.mrgentox.2010.06.012

9 Yuan Y, Sturgis EM, Zhu L, Lu M, Li Y, Wei Q and Li G: A functional variant at the miRNA binding site in $E 2 F 1$ gene is associated with risk and tumor HPV16 status of oropharynx squamous cell carcinoma. Mol Carcinog 56: 1100-1106, 2017. PMID: 27677255. DOI: $10.1002 / \mathrm{mc} .22576$

10 Kobayashi M, Fitz L, Ryan M, Hewick RM, Clark SC, Chan S, Loudon R, Sherman F, Perussia B and Trinchieri G: Identification and purification of natural killer cell stimulatory factor (NKSF), a cytokine with multiple biologic effects on human lymphocytes. J Exp Med 170: 827-845, 1989. PMID: 2504877. DOI: $10.1084 /$ jem.170.3.827

11 Stern AS, Podlaski FJ, Hulmes JD, Pan YC, Quinn PM, Wolitzky AG, Familletti PC, Stremlo DL, Truitt T and Chizzonite R: Purification to homogeneity and partial characterization of cytotoxic lymphocyte maturation factor from human Blymphoblastoid cells. Proc Natl Acad Sci USA 87: 6808-6812, 1990. PMID: 2204066. DOI: 10.1073/pnas.87.17.6808

12 Trinchieri G: Interleukin-12 and the regulation of innate resistance and adaptive immunity. Nat Rev Immunol 3: 133-146, 2003. PMID: 12563297 . DOI: $10.1038 /$ nri1001

13 Del Vecchio M, Bajetta E, Canova S, Lotze MT, Wesa A, Parmiani G and Anichini A: Interleukin-12: Biological properties and clinical application. Clin Cancer Res 13: 4677-4685, 2007. PMID: 17699845. DOI: 10.1158/1078-0432.CCR-07-0776

14 Macatonia SE, Hsieh CS, Murphy KM and O'Garra A: Dendritic cells and macrophages are required for Th1 development of $\mathrm{CD}^{+}{ }^{+}$T-cells from alpha beta TCR transgenic mice: IL12 substitution for macrophages to stimulate IFN-gamma production is IFN-gamma-dependent. Int Immunol 5: 1119-1128, 1993. PMID: 7902129. DOI: 10.1093/intimm/5.9.1119

15 Germann T, Gately MK, Schoenhaut DS, Lohoff M, Mattner F, Fischer S, Jin SC, Schmitt E and Rude E: Interleukin-12/T cell stimulating factor, a cytokine with multiple effects on T-helper type 1 (Th1) but not on Th2 cells. Eur J Immunol 23: 17621770, 1993. PMID: 8102100. DOI: 10.1002/eji.1830230805

16 Langowski JL, Zhang X, Wu L, Mattson JD, Chen T, Smith K, Basham B, McClanahan T, Kastelein RA and Oft M: IL-23 promotes tumour incidence and growth. Nature 442: 461-465, 2006. PMID: 16688182. DOI: $10.1038 /$ nature04808

17 Eisenring M, vom Berg J, Kristiansen G, Saller E and Becher B: IL12 initiates tumor rejection via lymphoid tissue-inducer cells bearing the natural cytotoxicity receptor NKp46. Nat Immunol 11: 1030-1038, 2010. PMID: 20935648. DOI: 10.1038/ni.1947

18 Le HN, Lee NC, Tsung K and Norton JA: Pre-existing tumorsensitized T-cells are essential for eradication of established tumors by IL12 and cyclophosphamide plus IL12. J Immunol 167: 6765-6772, 2001. PMID: 11739491. DOI: 10.4049/jimmunol. 167.12.6765

19 Brunda MJ, Luistro L, Warrier RR, Wright RB, Hubbard BR, Murphy M, Wolf SF and Gately MK: Antitumor and antimetastatic activity of interleukin 12 against murine tumors. J Exp Med 178: 1223-1230, 1993. PMID: 8104230. DOI: 10.1084/jem.178.4.1223

20 Jaime-Ramirez AC, Mundy-Bosse BL, Kondadasula S, Jones NB, Roda JM, Mani A, Parihar R, Karpa V, Papenfuss TL, LaPerle KM, Biller E, Lehman A, Chaudhury AR, Jarjoura D,
Burry RW and Carson WE, 3rd: IL12 enhances the antitumor actions of trastuzumab via NK cell IFN-gamma production. J Immunol 186: 3401-3409, 2011. PMID: 21321106. DOI: 10.4049/jimmunol.1000328

21 Ansell SM, Witzig TE, Kurtin PJ, Sloan JA, Jelinek DF, Howell KG, Markovic SN, Habermann TM, Klee GG, Atherton PJ and Erlichman C: Phase 1 study of interleukin-12 in combination with rituximab in patients with B-cell non-Hodgkin lymphoma. Blood 99: 67-74, 2002. PMID: 11756154. DOI: 10.1182/blood.v99.1.67

22 Little RF, Aleman K, Kumar P, Wyvill KM, Pluda JM, ReadConnole E, Wang V, Pittaluga S, Catanzaro AT, Steinberg SM and Yarchoan R: Phase 2 study of pegylated liposomal doxorubicin in combination with interleukin-12 for AIDS-related Kaposi sarcoma. Blood 110: 4165-4171, 2007. PMID: 17846226. DOI: 10.1182/blood-2007-06-097568

23 Yue T, Zheng X, Dou Y, Zheng X, Sun R, Tian Z and Wei H: Interleukin 12 shows a better curative effect on lung cancer than paclitaxel and cisplatin doublet chemotherapy. BMC Cancer 16: 665, 2016. PMID: 27549240. DOI: 10.1186/s12885-016-2701-7

24 Chen X, Han S, Wang S, Zhou X, Zhang M, Dong J, Shi X, Qian N, Wang X, Wei Q, Shen $\mathrm{H}$ and $\mathrm{Hu} \mathrm{Z}$ : Interactions of IL12A and $I L 12 B$ polymorphisms on the risk of cervical cancer in Chinese women. Clin Cancer Res 15: 400-405, 2009. PMID: 19118071. DOI: 10.1158/1078-0432.CCR-08-1829

25 Liu L, Xu Y, Liu Z, Chen J, Zhang Y, Zhu J, Liu J, Liu S, Ji G, Shi H, Shen H and Hu Z: IL12 polymorphisms, HBV infection and risk of hepatocellular carcinoma in a high-risk Chinese population. Int $\mathrm{J}$ Cancer 128: 1692-1696, 2011. PMID: 20521253. DOI: $10.1002 / \mathrm{ijc} .25488$

26 Shih LC, Tsai CW, Sun KT, Hsu HM, Shen TC, Tsai YT, Chang WS, Lin ML, Wang YC, Gong CL and Bau DT: Association of caspase-8 genotypes with oral cancer risk in Taiwan. In Vivo 33: 1151-1156, 2019. PMID: 31280204. DOI: 10.21873/invivo. 11585

27 Wu MH, Hung YW, Gong CL, Chao CC, Yueh TC, Wang SC, Lai YL, Hsu SW, Fu CK, Wang YC, Ke TW, Chang WS, Tsai $\mathrm{CW}$ and Bau DT: Contribution of caspase-8 genotypes to colorectal cancer risk in Taiwan. Anticancer Res 39: 2791-2797, 2019. PMID: 31177115. DOI: 10.21873/anticanres.13406

28 Wu MF, Wang YC, Li HT, Chen WC, Liao CH, Shih TC, Chang WS, Tsai CW, Hsia TC and Bau DT: The Contribution of interleukin-12 genetic variations to Taiwanese lung Cancer. Anticancer Res 38: 6321-6327, 2018. PMID: 30396953. DOI: 10.21873/anticanres.12989

29 Shen TC, Tsai CW, Chang WS, Wang S, Chao CY, Hsiao CL, Chen WC, Hsia TC and Bau DT: Association of interleukin-12a rs568408 with susceptibility to asthma in Taiwan. Sci Rep 7: 3199, 2017. PMID: 28600552. DOI: 10.1038/s41598-017-03523-0

30 Tao YP, Wang WL, Li SY, Zhang J, Shi QZ, Zhao F and Zhao BS: Associations between polymorphisms in IL12A, IL12B, IL12Rbeta1, IL27 genes and serum levels of IL12p40, IL-27p28 with esophageal cancer. J Cancer Res Clin Oncol 138: 1891-1900, 2012. PMID: 22740240. DOI: 10.1007/s00432-012-1269-0

31 Yin J, Wang X, Wei J, Wang L, Shi Y, Zheng L, Tang W, Ding G, Liu C, Liu R, Chen S, Xu Z and Gu H: Interleukin 12B rs3212227 $\mathrm{T}>\mathrm{G}$ polymorphism was associated with an increased risk of gastric cardiac adenocarcinoma in a Chinese population. Dis Esophagus 28: 291-298, 2015. PMID: 24529168. DOI: 10.1111/dote.12189 
32 Kaarvatn MH, Vrbanec J, Kulic A, Knezevic J, Petricevic B, Balen S, Vrbanec D and Dembic Z: Single nucleotide polymorphism in the interleukin $12 \mathrm{~B}$ gene is associated with risk for breast cancer development. Scand J Immunol 76: 329-335, 2012. PMID: 22702905. DOI: 10.1111/j.1365-3083.2012.02736.x

33 Ebadi N, Jahed M, Mivehchi M, Majidizadeh T, Asgary M and Hosseini SA: Interleukin-12 and interleukin-6 gene polymorphisms and risk of bladder cancer in the Iranian population. Asian Pac J Cancer Prev 15: 7869-7873, 2014 PMID: 25292079. DOI: 10.7314/apjcp.2014.15.18.7869

34 Roszak A, Mostowska A, Sowinska A, Lianeri M and Jagodzinski PP: Contribution of IL12A and IL12B polymorphisms to the risk of cervical cancer. Pathol Oncol Res 18: 997-1002, 2012. PMID: 22614250. DOI: 10.1007/s12253012-9532-x

35 Wang J, Nong L, Wei Y, Qin S, Zhou Y and Tang Y: Association of interleukin-12 polymorphisms and serum IL12p40 levels with osteosarcoma risk. DNA Cell Biol 32: 605-610, 2013. PMID: 23991654. DOI: 10.1089/dna.2013.2098

36 Huang ZQ, Wang JL, Pan GG and Wei YS: Association of single nucleotide polymorphisms in IL12 and IL27 genes with colorectal cancer risk. Clin Biochem 45: 54-59, 2012. PMID: 22040814. DOI: $10.1016 /$ j.clinbiochem.2011.10.004

37 Miteva L, Stanilov N, Deliysky T, Mintchev N and Stanilova S: Association of polymorphisms in regulatory regions of interleukin-12p40 gene and cytokine serum level with colorectal cancer. Cancer Invest 27: 924-931, 2009. PMID: 19832040. DOI: $10.3109 / 07357900902918486$
38 Sun R, Jia F, Liang Y, Li L, Bai P, Yuan F, Gao L and Zhang L: Interaction analysis of $I L 12 A$ and $I L 12 B$ polymorphisms with the risk of colorectal cancer. Tumour Biol 36: 9295-9301, 2015. PMID: 26104769. DOI: 10.1007/s13277-015-3685-7

39 Zhou L, Yao F, Luan H, Wang Y, Dong X, Zhou W and Wang Q: Functional polymorphisms in the interleukin-12 gene contribute to cancer risk: evidence from a meta-analysis of 18 case-control studies. Gene 510: 71-77, 2012. PMID: 22940148. DOI: $10.1016 /$ j.gene.2012.08.019

40 Zheng Y, Wang M, Tian T, Liu K, Liu X, Zhai Y, Lin S, Yang P, $\mathrm{Li} S$, Dai $\mathrm{Z}$ and $\mathrm{Lu} \mathrm{J}$ : Role of interleukin-12 gene polymorphisms in the onset risk of cancer: a meta-analysis. Oncotarget 8: 29795-29807, 2017. PMID: 28415696. DOI: 10.18632/oncotarget. 16080

41 Morahan G, Huang D, Ymer SI, Cancilla MR, Stephen K, Dabadghao P, Werther G, Tait BD, Harrison LC and Colman PG: Linkage disequilibrium of a type 1 diabetes susceptibility locus with a regulatory $I L 12 B$ allele. Nat Genet 27: 218-221, 2001. PMID: 11175794 . DOI: $10.1038 / 84872$

42 Davoodi-Semiromi A, Yang JJ and She JX: IL12p40 is associated with type 1 diabetes in Caucasian-American families. Diabetes 51: 2334-2336, 2002. PMID: 12086971. DOI: 10.2337/diabetes.51.7.2334

Received October 26, 2019

Revised November 4, 2019

Accepted November 5, 2019 